\title{
Community Gate Keepers' Awareness and Perception of Prevention of Mother- to-Child Transmission of HIV Services in Ibadan, Nigeria
}

\author{
Oyedunni S. Arulogun, ${ }^{1}$ Isaac F. Adewole, ${ }^{2}$ Lynda Olayinka-Alli ${ }^{3}$ and A. Olubukola Adesina ${ }^{2}$
}

\begin{abstract}
Each year, around half a million children aged under 15 become infected with HIV and more than $90 \%$ are the result of mother-to-child transmission. Services to prevent mother-to-child HIV transmission (PMTCT) are therefore important entry points for HIV/AIDS prevention, treatment and care services for women, their children and families. The study aimed at identifying level of awareness and knowledge of PMTCT services that can be utilized in improving access. The methodology consisted of 20 individual in-depth interviews spread over Adabeji, Adeoyo/Agbadagbudu, Jakiru/Onipasan and Eleta communities, in Ibadan among household heads, religious and community based leaders. Key factors identified were low knowledge of mother to child transmission, lack of knowledge of the PMTCT services, inadequate community sensitization, inadequate healthcare facilities. The success of PMTCT programmes demands a shift towards a more community-based approach which calls for strong advocacy, enlightenment and community mobilization for improved awareness and utilization of PMTCT services. (Rev Afr Santé Reprod 2007; 11[1]:67-75)
\end{abstract}

\section{RÉSUMÉ}

La conscience et la perception des services de la prévention de la transmission du VIH de la mère à l'enfant à Ibadan chez les gardiens de la communauté Chaque année environ un demi million d'enfants âgés de moins de 15 ans sont infectés du VIH et plus de $90 \%$ sont les résultats de la transmission de la mère à l'enfant. Les services destinés à la prévention de la transmission de la mère à l'enfant (PTME) sont donc les points d'entrée pour la prévention du VIH/ SIDA, le traitement et les services de soin pour les femmes, leurs enfants et leurs familles. L'étude avait pour but d'identifier le niveau de conscience et de connaissance de services de la PTME dont on peut se servir pour améliorer l'accès. La méthodologie comprenait 20 interviews en profondeur qui couvraient ces communautés: Adabeji, Adeoyo/Agbadagbudu, Jakiru/Onipasan et Eleta à Ibadan au sein des chefs de foyers, les leaders religieux et des communautés. Parmi les facteurs clé identifiés étaient une connaissance faible de la transmission de la mère à l'enfant, le manque de connaissance à l'égard des services de la PTME, une sensibilisation inadéquate de la communauté, l'insuffisance des services de santé. Le succès des programmes de la PTME exige une réorientation vers une approche qui est basée sur la communauté qui nécessite un plaidoyer efficace, une sensibilisation et une mobilisation de la communauté pour permettre une meilleure conscience et une meilleure utilisation des services de la PTME. (Rev Afr Santé Reprod 2007; 11[1]:67-75)

KEY WORDS: awareness, perception, PMTCT services, community gate keepers

${ }^{1}$ Department of Health Promotion and Education, College of Medicine, University of Ibadan ${ }^{2}$ Department of Obstetrics and Gynaecology, College of Medicine, University of Ibadan Department of Primary Health Care Tutor's Course, University College Hospital, UCH, Ibadan

Correspondence to Dr. Oyedunni Arulogun, Department of Health Promotion and Education, College of Medicine, University of Ibadan. Email: omoyisola2002@yahoo.com, fax: 234-2-2411768

Introduction 
Everyday, approximately 5,000 women are newly infected with HIV, and more than 3,000 die from AIDS related illnesses ${ }^{1}$. In most parts of the world HIV infection is increasing faster among women than men. Nowhere is the trend more apparent than in sub-Saharan Africa where women comprise $58 \%$ of existing HIV infections ${ }^{2}$. These differences in infection rates are due to a combination of factors. Women and girls are commonly discriminated against in terms of access to education, employment and land inheritance. With increasing poverty levels, African women have found themselves in casual relationship with men as this can serve as a conduit for financial and social security. Women therefore find it difficult to demand safe sex, as they become subordinates or dependents of mainly older men. Women are also biologically prone to infection and HIV is easily transmitted from men to women than the reverse.

This has led to the increase in women living with HIV. Results of initial early studies analyzing progression and survival in HIV disease suggested a difference based on gender. Most of these studies indicated that the prognosis for women was worse than for men. This reflected late access to limited care ${ }^{3,4,5}$. Lack of access to care, minimal self-motivation, and attention to the health care of their children over that of themselves all contributed to decreased rates of early detection and intervention. HIV and AIDS for women therefore is an issue of access to health care ${ }^{6}$.

The principal mode of transmission of HIV in Africa is heterosexual. The second is mother to child transmission, which is the main mode of acquisition of HIV infection in children, under 15 years. The number of children living with HIV infection is estimated at 2.5 million since the epidemic began 7 . Each year, around half a million children aged under 15 become infected with HIV. Almost all of these infections occur in developing countries, and more than $90 \%$ are the result of mother-to-child transmission during pregnancy, labour and delivery, or breastfeeding. Without interventions, there is a $20-45 \%$ chance that a baby born to an HIV-infected mother will become infected ${ }^{8}$. Vertical transmission rates of HIV are estimated to be $15-25 \%$ in industrialized nations and $25-45 \%$ in developing countries ${ }^{9}$. The most effective means of reducing mother-to-child transmission is to provide fully suppressive ART to the mother in the long term, thereby not only reducing the risk of vertical transmission, but also sustaining the life and health of the mother while the child is growing up.

HIV/AIDS has therefore become a critical development issue in most sub-Saharan Africa nations ${ }^{10,11}$ where a disproportionate number of all HIV/AIDS infections occur. HIV prevalence is now as high as $40 \%$ among antenatal care attendees in some parts of Africa ${ }^{12,13}$. In 2004, an estimated 28 million adults and children were living with HIV/AIDS in sub-Saharan Africa, making it by far the region most affected by the epidemic. With only 10 percent of the world population, sub-Saharan Africa accounted for at least 75 percent of the estimated 3 million global AIDS deaths in $2004^{14}$. To address the escalating HIV/AIDS burden, government health departments are reallocating health resources, shifting the training and deployment of health personnel, and changing the overall organization of the public health infrastructure. Consequently, the region has seen an expansion of HIV prevention and care programs and services, such as prevention of mother-to-child transmission (PMTCT) programs, Voluntary Counseling and Testing (VCT) centers, provision of anti-retroviral therapy (ART), and home-based care. As a result challenges involved in preventing mother-to-child transmission are now greater than envisaged and progress has not been as expected. This has a great implication on the future of any society, as there will be nobody to take care of the future if nothing is done to reverse this trend. Furthermore, women face a lot of discriminations as well as obstacles in making decisions pertaining to their health as well as in health seeking behaviour. 
Furthermore, where drugs are available to prevent this mode of transmission during pregnancy, a lot of people cannot afford it due to the cost. Therefore creating widespread community awareness starting with the gate keepers is an essential step in improving accessibility of PMTCT services they have a crucial role to play in reducing this discrimination and stigma as well as promote utilisation of the services.

It is in this view that the level of opinion leaders' awareness and perception of prevention of mother-to-child transmission of HIV services are investigated.

\section{Methodology}

The study was a descriptive qualitative study that utilized in-depth interviews. Qualitative study method was chosen because of its usefulness in exploration of people's knowledge views and experiences ${ }^{15}$. The other advantage of qualitative methods is that they can be participatory, democratic and empowering. This may result in development of new perspectives and attitudes that are health promoting ${ }^{16}$. Use of open-ended questions in in-depth interviews allowed the participants to express themselves in their own vocabulary that would be difficult in close-ended questions characteristic of quantitative methods.

\section{Study setting}

The study was conducted in Adabeji, Adeoyo/ Agbadagbudu, Jakiru/Onipasan and Eleta, communities in Ibadan. Ibadan is one of the cities that house the institutions where the AIDS Prevention Initiative (APIN) activities are in place. There are 2 hospitals (University College Hospital and Adeoyo Maternity Hospital) that provide full PMTCT services and 8 other centers (St Mary's General Hospital, Victory Medical Center, Primary Health Care (PHC) facilities in Oranyan, Agbongbon, Idi-Ogungun, Omotayo Maternity Centre and Royal Crown Hospital) that provide only Voluntary Counseling and Testing (VCT) services. Women with positive results are referred to the hospitals where the full PMTCT services can be accessed. At the time of the study, the APIN PMTCT project at the University College Hospital was at the planning stage for the scaling up of the PMTCT services.

\section{Data collection methods}

A research team consisting of the principal investigator, HIV/AIDS counsellor was assembled to conduct the study. Training on qualitative research was conducted for the six research assistants ( 3 males and 3 females). An in-depth interview guide was designed in English and translated to the local language, Yoruba which was pretested among persons of similar characteristics in Mokola area of Ibadan. In-depth interviews were conducted with key informants who included community leaders like religious leaders, leaders of community based organisations and household heads. These were selected in conjunction with the existing leadership structures such as the mogajis and the baalès in the communities. Topics covered were: Issues in the guide included awareness and knowledge of HIV/AIDS, knowledge of mother-to-child transmission of HIV, mandatory screening, attitude towards pregnant women infected with HIV, services to assist pregnant women with HIV, information needed to help pregnant women with HIV. In most instances the interviews took place at the participants' homes at times convenient for them after advance booking. A brief explanation of the aim of the study and confidentiality related issues kicked off the interview. At the end of the interview, debriefing was carried out and some quotations were read back to the participants especially on some important points. Generally interviews were carried out in a harmonious, friendly and open atmosphere. Each interview lasted about one hour. During the interview, data was recorded by taking hand written notes and tape recorder. 


\section{Data analysis}

Concurrent data collection and analysis strategy was used to enable researchers to go back and refine questions and make more inquiry into emerging issues. After the field study, the written and recorded materials were transcribed to English. The actual analysis began with reading through the transcribed interviews and listening to the audio records in order to get a good grasp of all the data. The key ideas and emerging themes were identified and themes from different groups were pooled together and integrated into common themes. This was then followed by generation of concepts that were used to organize the presentation of the findings.

\section{Findings}

\section{Demographic characteristics}

Twenty opinion leaders comprising 12 males and 8 females participated in the indepth interviews. The median age was 50 years, ranging from 45 to 65 years. Respondents were made up of religious leaders, heads of households, and leaders of community based organisations.

\section{Community Gate Keepers' awareness and knowledge of HIV/AIDS}

In order to get an insight into the gate keepers' understanding of HIV/AIDS, participants were asked to state what they understood by the term HIV/AIDS in their settings. The following is their understanding of what HIV/AIDS is, they said it is "arun ti ko gbogun" that is a disease that has no cure. The presence of such local definitions is an indication that HIV/AIDS is among the people. One participant said he "knew a family with members dying of HIV" and another said he has a friend "who lost a child to HIV". The commonest sources of HIV/AIDS information were the television and radio. However, one participant said he does not believe that AIDS is in Nigeria. The modes of transmission as listed by participants were indiscriminate sexual intercourse, sex with commercial sex workers, use of contaminated needles, contaminated clippers at barbers shop, blood transfusion and unprotected sex. On whether the participants could identify people living with HIV, various responses were given such as through "weight loss, "one cannot recognize such", "one may not know until it gets to the advanced stage". A respondent was categorical and said "HIV positive persons can only be recognized through HIV screening". When asked the types of persons that participants considered to be at risk of HIV infection, responses given varied as they mentioned promiscuous people, commercial sex workers and everybody. Overall HIV was viewed as a disease which is not restricted to any particular age group. Responses peculiar to female group are "those going to quacks" while for male group people at risk are "people not careful about source of sharp objects, people with multiple partners and people with multiple wives". Known preventive methods were also used to measure the knowledge of participants. Various prevention methods were cited by participants. For the male participants, "the use of condom", "abstinence", "the use of sterilized clippers", "to avoid shaving with sharp objects", "abstinence from sin", "having only one partner", "obeying the will of Allah", "eating balanced diet", "faithfulness to partner", "obtaining information from medical personnel on prevention" and "young people going for HIV screening before marriage" were listed as preventive measures while the females, mentioned "abstinence", "cleaning of dirty environment", "using condom" and "faithfulness to one's partner".

\section{Mother - to - Child Transmission of HIV}

The participants generally understood the modes of HIV transmission but were not conversant with mother-to-child mode of transmission as they did not mention it while listing different modes of transmission until prompted. The commonest source of information was the radio. 
When participants were asked to mention where most transmission occurred during mother to child transmission, breast feeding and pregnancy were the commonest. Other means mentioned by male participants were "through wounds, sharing needles with other women in the hospital, from her husband, through extramarital affairs, use of contaminated sharp objects, kissing, indiscriminate sex, from hairdressing saloon, receiving treatment from quack doctors and from her mother". For the females, the means were "through sharing of toilet facilities, being promiscuous, through contaminated needles and unfaithfulness to husband before pregnancy is confirmed". These means were fraught with misconceptions.

Common themes on prevention of mother to child transmission of HIV as listed by participants during the interviews were: "that the pregnancy woman should give birth in hospital where HIV positive women are given treatment", "pregnant women are to avoid sharp/ contaminated objects", "pregnant women are to register only in government hospitals", "pregnant women should not share toilets", "pregnant women should go to doctors for treatment", "women should not be promiscuous by not having extramarital affairs" and "pregnant women should go to hospital for regular check up" (male participants). Female participants on the other hand mentioned "personal hygiene", "avoiding sharp objects", "being faithful to husband", "regular treatment", "taking injections" and "avoiding treatment from ward maids".

In addition, respondents were also asked in what ways HIV positive pregnant women can be of danger to their unborn child. Responses given were that the unborn child has a great chance of being infected from the womb through the placenta, breastfeeding, sharing sharp objects with child and through blood transfusion. However one respondent said that "mother cannot transmit HIV if God has not destined that child to have HIV".

African Journal of Reproductive Health Vol. 11 No.1 April, 2007

\section{Attitudes towards routine testing of pregnant women}

One of the objectives of the current PMTCT program is to counsel all pregnant women for HIV testing. Those who want the test are then offered. There is no routine HIV testing without the consent of the woman. The study wanted to establish what the participants thought about routine testing of pregnant woman. All participants but one said HIV screening for all pregnant women is good. Reasons adduced are that "it will help people to know their status", "it is good for the mother and unborn child and can help protect against infection if not infected already". The consensus was that the best approach would be to make HIV testing a normal test done to pregnant women just like other tests.

Care considered necessary for pregnant women who are HIV positive as elucidated by participants were: for the male participants special care included provision of necessary drugs, going to the hospital and using her drugs regularly, drugs should be made available and they should be told how to use it, pregnant women who are HIV positive should be separated from people and given proper medical attention as well as government to provide special care hospital. For their female counterparts, special care listed include going to hospital for treatment and using drug regularly, doctors be giving them necessary drugs, receiving regular treatment before delivery, lectures should be given and pregnant women should be given necessary care since the disease is incurable.

When asked who should be responsible for this special care more male participants than female said government. Other persons mentioned were the husband, the family, orthodox and traditional medical practitioners. Reasons adduced for government being the responsible organ to provide the care is that they have all the money to execute the programmes and supply the drugs. Reasons for the husband 
and family were more because of social support and for the medical personnel because of the professional skill in taking care of the sick.

\section{Attitude of Respondents to pregnant women who are HIV positive}

Attitudinal disposition of opinion leaders to pregnant women who are HIV positive was assessed. Responses were on a continuum from stigma, discrimination, ostracism, abandonment to support. For male participants, attitudinal dispositions expressed in their words were: "we will show love to her", "there will be no change in attitude", "our attitude will be normal towards her", she will not be discriminated against", "we will not run away from her but will give necessary advice", "we will not move close to her", "we will discriminate by isolating her". The religious leader said "he would pray for her and she prays for herself". The female participants on the other hand expressed the following attitudinal disposition as listed in their words: "I will avoid pregnant women with HIV", "I cannot say because I have not seen one before", "I will be caring e.g. cook for her, will counsel and encourage her, will play with her and will avoid sharing sharp instrument with her".

When asked how they would assist any pregnant woman who is HIV positive, respondents said they will "assist financially, advice her to go to the hospital for treatment will pray for her and will say words of comfort to her".

\section{Opinion towards HIV positive woman intending to get pregnant}

Participants were asked what their opinions were towards a woman positive for HIV intending to get pregnant, opinions included "she should not get pregnant as child is at risk", "she should first treat self before thinking of pregnancy", "she should not bother to get pregnant", "she should not get pregnant because of man and baby who would be put at risk", "I would pray for her and wish her safe delivery", "there is nothing bad in getting pregnant, I will wish her good luck", "she should seek advise and should not get pregnant except she is healed". For the female participants, opinions expressed were: "she would be advised to cure herself before getting pregnant", "I will advise her to forget about pregnancy because there is no future for such a child since the child will eventually die" and "the woman should abstain from pregnancy so as to avoid transmitting the virus to the unborn child".

\section{Awareness of PMTCT Services}

Participants were asked if they were aware of PMTCT services. To this question half of the respondents said they were aware. Their source of awareness was the newspaper. None of the respondents could mention any community sensitization programme on PMTCT within their communities neither could they recall any planning process in which they were involved as far as PMTCT services are concerned. When asked to mention where the services are rendered, respondents mentioned University College Hospital and Adeoyo Hospital in Ibadan and Faith Hospital Oyo. The rest did not know anything about PMTCT services. On the adequacy of the health facilities, the opinion leaders interviewed were of the opinion that the services are not enough. The leaders from Adabeji said the facilities available were too far off from their community and pregnant women had to spend a substantial amount of money on transportation to get to the facility nearest to them. When asked if they were aware of any pregnant woman accessing the PMTCT services, all of the respondents did not know any woman utilizing the services.

\section{Discussion}

This study was designed to determine whether the community gate keepers were aware of mother to child transmission of HIV, its prevention, attitudes towards routine testing of 
pregnant women, attitude to pregnant women who are HIV positive, opinion towards HIV positive woman intending to get pregnant and awareness of PMTCT services. Such information is important in designing appropriate intervention messages for the scaling up of PMTCT services using the community gate keepers as the spring board. For the community to actively participate in health promotion programmes, it is important to know whether they understand the health issue and whether they view a targeted health problem as a threat to them. It is against this background that the study set out to assess whether the communities were aware of PMTCT services for the prevention of HIV in children. There were many local definitions of HIV/AIDS. These included an incurable disease and a deadly disease. The fact that HIV/AIDS has local definitions shows that disease is among the people. The level of community knowledge about HIV influences the context within which communities make decisions about the prevention of mother to child transmission of HIV. Health promoters should harness that knowledge and incorporate it into the health promotion programmes. The participants in this study showed a high level of knowledge about the major modes of transmission of HIV except the mother-to-child route. They cited that HIV transmission was commonest during pregnancy and breast feeding. The findings in this study are similar to those of Mukuka (2000), Orji et al (2001) and Nyblade et al (2001) in Zambia, Nigeria and Botswana respectively. In these studies, communities thought that most transmission occurred during pregnancy. There is the need to correctly inform the community about what time in pregnancy that transmission occurs. This will invariably motivate women supported by the community to take medication if they are aware. It is discouraging to note that community leaders still mention non-transmission routes as transmission routes. This is a pointer to the need to revisit the awareness campaigns messages aired through the various media and see how they can be modified to suit the communities and reduce the miscon-ceptions.

Participants had a vague idea of the methods of prevention of mother to child transmission of HIV which they reportedly heard from the radio and read in newspapers. This finding concur with those of Kayode et al 2003 and Nyablde et al 2001 who found that the knowledge about mother to child transmission of HIV, including prevalence, points of transmission during pregnancy, delivery and breast-feeding is lacking. In these studies, participants could not specify the precise mechanism. Health workers therefore need to understand this gap in knowledge in order to develop appropriate messages to the community. Most participants were aware of the availability of HIV counselling and testing services at the hospital. The main reason for seeking an HIV test was cited as knowing one's status. The advantages of knowing one's status included sexual behaviour change by using condoms and desisting from having multiple sexual partners, getting counselling and other support services including early treatment if one was HIV positive. A multi-country study on the efficacy of HIV VCT demonstrates the important role of VCT as an HIV preventive strategy (Gregorich et al 1998, Voluntary Counselling and Testing Study Group (2000). In these studies, there was increased condom use and fidelity to one partner following VCT. It is encouraging to note that the participants were aware of the benefits of VCT.

Most participants in this study were supportive of routine prenatal HIV testing. Simpson et al (2003) found similar findings in the United Kingdom. In their study, most women found HIV testing to be acceptable as a routine test. This has resulted in some health authorities adopting this "opt out" approach to prenatal testing (Jayaraman $G$ et al 2003). Under this approach, HIV testing is routinely done for all pregnant women seeking prenatal care unless they specifically choose not to be tested as opposed to the "opt in" approach where women actively 
choose to be tested themselves. When the "opt out" approach was introduced in Alberta, Canada, there was a dramatic and sustained increase $(28 \%)$ in rates of prenatal HIV testing (Jayaraman G et al 2003). Similar trends have been reported in the United Kingdom and United States (Stringer E et al 2001, Simpson et al 1999, Blott et al 1999). It is $t$ therefore important for health workers to understand some of the reasons why women might not seek HIV testing in pregnancy in spite of being aware of the advantages.

\section{Limitations of the study}

Purposive selection of gatekeepers who took part in the interviews may have introduced some selection bias. Views presented may therefore not be representative of that group. However, one of the strengths of the study was the category of participants interviewed. These are influential people in their communities who can be used to reach members of their communities to access PMTCT services. In addition, the incorporation of their views and opinions in health promotion messages may lead to greater PMTCT acceptance.

Based on these findings there is need for strong advocacy, enlightenment and community mobilization for improved awareness and utilization of PMTCT services. These opinion leaders therefore could be involved in developing a locally appropriate PMTCT communication for change framework.

\section{REFERENCES}

1. UNAIDS Global Estimates of HIV/AIDS Epidemic as of END of 2001, 2002 July.

2. UNAIDS AIDS Epidemic Update: 2002 December.

3. Bastian,L., Bennet, C.L., Adams, J., Waskin,H., Divine, G., \& Edlin, B.R. Differences between men and women with HIV-related Pneumocystis carinii pneumonia: experience from 3,070 cases in New Uork City in 1987. J Acquir Immune Defic Syndro.1993 Jun: 6(6): $617-23$.

4. Melnick, S.L., Sherer, R., Louis, T.A., Hillman, D., Rodriguez, E.M., Lackman, C., Capps, L., Brown,
L.S.Jr, Caryln, M., Korvick, J.A. et al (1994) Survival and disease progression according to gender of patients with HIV infection. The Terry Beirn Community Programs for Clinical research on AIDS. JAMA, 1994 December28:272 (24): 1915-21.

5. Sherer, R., Melnick, S., Hillman,D. et al HIV-related clinical events and mortality: Preliminary observation data from the Community Programs for Clinical Research on AIDS (CPCRA) (09.55).In Program and Abstracts of the 1992 VIII International AIDS Conference, Amsterdam, The Netherlands.

6. UNAIDS (2003). AIDS epidemic update. December 2003, Geneva, Switzerland.

7. Currier, J. S. et al (1992) Women and power: The impact of accrual rates of women on the ability to detect gender differences in toxicity rates and response to therapy in clinical trials. In: Program and Abstracts of the 1992 VIII International AIDS Conference, Amsterdam, The Netherlands.

8. De Cock K.M. et al (2000), Prevention of motherto-child HIV transmission in resource-poor countries: translating research into policy and practice, JAMA, 2000 March 283(9)

9. Msllati, P., Leroy, V., Lepage, P. et al (1992) Natural history of HIV-1infection in African women: A prospective cohort study in Kigali (Rwanda) 19881991 (10.35). In: Program and Abstracts of the 1992 VIII International AIDS Conference, Amsterdam, The Netherlands.

10. Boerhringer Ingelheim International Prevention of Mother - to - Child Transmission of HIV-1: The Role of Nevirapine.2001

11. USAID's Expanded Response to HIV/AIDS. United States Agency for International Development, Washington D.C., 2002 June.

12. Welty, T. and Welty, E. Personal Communication. Life Abundant Primary Care Program (LAP), Cameroon, 2002 November.

13. Wilfert, C. Personal Communication. Scientific Director, Elizabeth Glaser Pediatrics AIDS Foundation, 2002 October.

14. UNAIDS. End-2004 global HIV and AIDS estimates, www.unaids.org 2005.

15. Kitzinger J. The methodology of focus groups: the importance of interactions between research

African Journal of Reproductive Health Vol. 11 No.1 April 2007 

participants. Sociology of Health and Illness; (1994)16:103-21

16. Kitzinger J. Introducing focus groups. BMJ; (1995).311:299-302.

17. Mukuka C. Mother to Child Transmission Intervention: a report on formative research conducted in Chipata Health Centre and its catchment area. Ministry of Health, Zambia. (1999)

18. Orji EO, Sotiloye D, Fawole AO et al. Attitude of Abeokuta pregnant women to routine human immunodeficiency virus screening. Nigerian Journal Med; (2001) 10(4):173-6

19. Nyblade L, Field ML. Women, communities and Prevention of Mother to Child Transmission of HIV: Issues and findings from community research in Botswana and Zambia. International Council for Research on Women, Population Council, June. (2001)

20. Kayode CM, Adeyemo AA; Omotade OO Beliefs and perceptions about HIV infection and AIDS among mothers of infants in Ibadan, Nigeria; West Afr J Med (2002).21(1):43-7.

21. Gregorich S, Kamenga C, Sangiwa G.. Impact of HIV counselling and testing on married couples in three developing countries: results from the voluntary counselling and testing study. Paper presented at the $12^{\text {th }}$ World AIDS conference, Geneva. (1998)

22. Voluntary HIV-1 Counselling and testing efficacy group. Efficacy of Voluntary HIV- 1 counselling and testing in individuals in Kenya, Tanzania and Trinidad: a randomised trial. The Lancet, (2000) 356:103-112.

23. Jayaraman G, Preiksaitis J, Larke B Mandatory reporting of HIV infection and out out prenatal screening for HIV infection: effect on testing rates. CAMJ (2003);168(6): 679-82

24. Stringer EM, Stringer JS, Cliver SP et al. Evaluation of a new testing policy for human immunodeficiency virus to improve screening rates. Obstet Gynecol; (2001) 98(6):1104-8.

25. Simpson WM, Johnstone ED, Goldbert DJ et al. Antenatal HIV testing: assessment of a routine voluntary approach. BMJ; (1999)318:1660-61

26. Blott M, Yearwood J, Gerval M et al Routine antenatal testing is acceptable to women. BMJ; (1999).319:1069-70. 